\title{
The Pursuit of Essence: Realizing Expansion and Oneness by Limitation
}

\author{
Birgit Penzenstadler \\ birgitp@chalmers.se \\ Chalmers|Gothenburg University, Lappeenranta Lahti University \\ Planet Earth (for now)
}

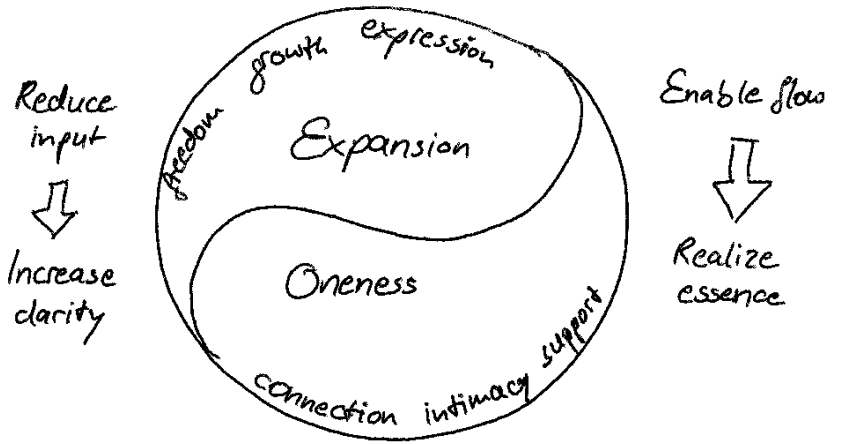

Figure 1: Expansion and Oneness - fundamental human desires as experienced by the author.

\begin{abstract}
What do Insight Timer, Clubhouse, Muse, the Breathing App, ReMarkable and some select Podcasts have in common? They can trigger flow and they work with limited input and resources. While plugged in, some of them talk dedicatedly about unplugging and what is essential. As humans, we have a deep desire for expansion and oneness. Sometimes these two wishes seem to be opposing each other, but it really depends on how we address them. This paper sheds light on how an exemplary, personal selection of mobile applications can help or hinder, as per autoethnographic exploration. While mobile applications are not the answer, they can support us in the pursuit of essence in both directions in deliberate use. I point out some resulting questions and wonder how to live into them, maybe (but just considering) via a proposed hypothetical system.
\end{abstract}

\section{CCS CONCEPTS}

- Human-centered computing $\rightarrow$ HCI theory, concepts and models; Heuristic evaluations; • Applied computing $\rightarrow$ Psychology.

\section{KEYWORDS}

neuroplasticity, expansion, oneness, connection, essence, clarity, cognitive models, storytelling, transcendence, autoethnography, technology

Permission to make digital or hard copies of part or all of this work for personal or classroom use is granted without fee provided that copies are not made or distributed for profit or commercial advantage and that copies bear this notice and the full citation on the first page. Copyrights for third-party components of this work must be honored. For all other uses, contact the owner/author(s).

LIMITS '21, fune 14-15, 2021,

(c) 2021 Copyright held by the owner/author(s).
Reference Format:

Birgit Penzenstadler. 2021. The Pursuit of Essence: Realizing Expansion and Oneness by Limitation. In LIMITS '21: Workshop on Computing within Limits, fune 14-15, 2021.

\section{INTRODUCTION}

According to the research of Ashley Whillans and Elizabeth Dunn [26], how you choose to spend your time is the single most important indicator for your happiness. Taking this back to ancient teachings, the only time I can truly live in is the present moment - the past is gone, the future is not here yet [15]. So while I may spend a few minutes happily reminiscing about the past or looking forward to something in the future, the deepest bliss is only accessible in the here and now. If I spend too much time hanging out in the past or future in our minds, then the present moment becomes evasive, because our mind is used to being pulled away from it. So in addition to deliberate practice of spending time in the Now, how I spend that time naturally becomes the most important indicator for happiness.

I explore this notion under the acknowledgement that I spend a certain amount of hours in a day to take care of obligations. The call for papers encourages authors "to consider the stories they tell and reify through their work. " because 'Stories have power'. Leaning on Sasha Constanza-Chock's words, this year I explore "what stories are told about design problems, solutions, contexts, and outcome? Who gets to tell these stories? Who participates, who benefits, and who is harmed?" [6, p. 134]

The first author of this paper is highly interested in individual resilience, sustainability, and well-being, as the individual forms the basic unit for a healthy community that can care for the natural environment and build a supportive society. At the core of human beings are fundamental desires for oneness and expansion. Such 
desires can be satisfied in many different ways, so I often seek to return to the essence when I get overwhelmed, and I value states of flow where I am in an almost effortless pursuit of our desires.

This study investigates in an auto-ethnographic approach how the pursuit of oneness and expansion benefits from limitation of input, and how technology can support and hinder that. I set out to explore the use of technology in a small set of apps that have proven useful to me in various aspects of navigating this pursuit. The study draws from journal notes over the past 12 months. I discuss questions that come up along the way and how to live into them.

I start by explaining the foundational background, offer an insight into the process of the pursuit, and discuss the impacts and resulting insights.

\section{BACKGROUND: THE ESSENCE}

\subsection{Perception of Oneness and Expansion}

The following description of the core human desires for oneness and expansion stems from my personal experience and therefore does not contain references to literature. While I have taken many insights from various ancient teachings, yogic as well as shamanistic lineages, there is no source to refer to for this piece. It is my lived experience, and it is a basic premise and theoretical foundation for the paper at hand.

I acknowledge that my personal life's experience is strongly shaped by the privileges I happened to be born into. I do not wish to impose my perception onto others and only offer it as lens that one can choose to look through.

If I am in the privileged position of having our basic needs met, I tend to desire both oneness and expansion, which I can see as a parallel to how the universe works, in contraction into singularity and expansion, in alternating waves. How one experiences these two tendencies can take many different forms of expression and differs according to cultural context, physical environment, and individual life experience.

While scientific literature identifies more than two, e.g. Reiss identified 16 basic desires [22] (Power, Curiosity, Independence, Status, Social contact, Vengeance, Honor, Idealism, Physical exercise, Romance, Family, Order, Eating, Acceptance, Tranquility and Saving), they can all be traced back to one of the two core desires even a hunger for power is a desire for freedom and connection at the same time.

The life force running through us is an experience of oneness and expansion and freedom is an experience of oneness and expansion. I am that life energy, also known as 'universal love', and I am free. I think I am a separate individual and it seems that this is our core wound as humans. Our challenges stem from the illusion that we are separate.

If the life energy that runs through everything is what truly holds our capacity to experience this life, then let us express it more fully, let us see the beauty in every breath, in every eyesight, in every scent I perceive, in every touch our skin gets to experience, and in every heartbeat. Notice the miraculous - surpass thought and be in observance. Be in the body, experiencing, not thinking, just witnessing the miracle of life. When I become perceptive of the miraculous I become void of the barriers I struggle to maintain to keep out the expansion of receiving. Love is the unabashed experience of life.

For these two core desires, for oneness and for expansion, I differentiate three aspects that help characterize the experience, as shown in Fig. 1: Freedom, growth, and expression are aspects of Expansion, and connection, intimacy, and support are aspects of Oneness. As the Yin Yang illustration in Figure 1 depicts, both together form a whole. Someone striving for expansion only may find themselves experiencing a feeling of 'never enough' and of disconnect, and someone striving only for oneness may find themselves experiencing the other side of the feeling of 'never enough' and of constriction.

\subsection{Limitation and Essence}

In his book "Essentialism: The disciplined pursuit of Less" [20], Greg McKeown lays out the premise that with the amount of information input that each of us are exposed to every day, we are prone to be overwhelmed at some point and at the same time longing for something else. He offers five simple questions to evaluate that: Have you ever found yourself stretched too thin? Do you sometimes feel overworked and underutilized? Do you feel motion sickness instead of momentum? Does your day sometimes get hijacked by someone else's agenda? Have you ever said 'yes' simply to please and then resented it?

By applying a more selective criteria for what is essential, the pursuit of less proposes to regain control of our own choices to channel our time, energy and effort into making the highest possible contribution toward the goals and activities that matter. Essentialism is not seen as a tool but as a mindset; a way of life. The ideas in this book are not new, but a good reminder to things we know and tend to forget because we get 'busy' and it is so easy to get distracted.

Within the research community that addresses Limits to Growth and environmentalism, constraints are set by the capacity limits of our physical planet, and we need to understand that "less is more" to implement 'degrowth' [13]. In this context, Kallis differentiates between externally and internally imposed limits, and suggests redirecting our focus from nature's limits to processes of civilisation and decivilisation [16]. This will allow us to stay within a safe operating space on this planet [23].

From the perspective of indigenous wisdom, where plants and animals are our oldest teachers, we learn about our desire for connection and oneness under a different lens, in acknowledging ourselves as part of nature. Understanding this is a foundation for living in "right relationship" with the world around us, the medicine path of the Cherokee people [12]. Kimmerer [17] weaves a botany narrative that leads us to the understanding that the awakening of a wider ecological consciousness requires our reciprocal relationship with the rest of the living world. She concludes [17, p. 382] "The gifts of the earth are to be shared, but gifts are not limitless. The generosity of the earth is not an invitation to take it all."

While these works come from very different backgrounds and communities, they all invite us to reflect upon our relationship with the world at large and what is truly essential to us. 


\subsection{Flow}

An important ingredient of well-being and long-term resilience is knowing what allows us to get into states of flow, so we can work and serve well. According to Kotler [18], flow produces 5 important chemicals in our brain, it is autotelic (addictive), and the highest intrinsic motivation possible. And while Kotler researches high performance, he does so under the lens of long-term sustainability of the individual, not a quick squeezing of maximum performance until burnout, but how to train, recover, perform, and sustain over the long run. This includes adequate phases of recharge and reset.

When do you get into the zone? Mihaly Csikszentmihalyi [7] defines this state as "being so involved in an activity that nothing else seems to matter: The ego falls away. Time flies. Every action, movement and thought follows inevitably from the previous one, like playing jazz. Your whole being is involved, and you're using your skills to the utmost." In research, he found they exist not only in surfing or solely in athletics, but also in activities as wide-ranging as painting and chess playing and heart surgery. To describe such moments, athletes often use the term in the zone, while psychologists prefer flow state. When people are entrenched in such a state, as Csikszentmihalyi points out in his book Flow, "they stop being aware of themselves as separate from the actions they are performing." In other words, time and space vanish, and so does the self. If this sounds similar to the phrasing often used to describe so-called spiritual experiences, that is not without reason.

\subsection{Transcendence}

Since Csikszentmihalyi's flow research, likewise interested scientists have begun utilizing more advanced personality profiles like the Temperament and Character Inventory created by Robert Cloninger $[3,10]$. The TCI is a widely respected and often utilized personality profiles, which was extensively validated. It is designed to consider not simply the psychological factors of personality but social, environmental, biological and neurochemical components as well. The TCI was one of the first personality profiles to measure a trait known as 'self-transcendence', a term is used to describe spiritual feelings independent of traditional religiosity.

As Frankl writes [9]: "Human existence is not authentic unless it is lived in terms of self- transcendence. Self-actualization is an unintentional effect of the intentionality of life. Self-transcendence is the essence of existence." and Maslow [19] defined it as follows:

Transcendence refers to the very highest and most inclusive or holistic levels of human consciousness, behaving and relating, as ends rather than means, to oneself, to significant others, to human beings in general, to other species, to nature, and to the cosmos.

Self-transcendence is composed of three components: Transpersonal identification, mysticism, and self-forgetfulness.

(1) Transpersonal identification is a form of empathy at large [11]. It's a willingness to identify not just with fellow humans but with plants and animals and even the planet itself, and has been measured by Cloninger [3] in an instrument with constructs like this statement: "I sometimes feel so connected to nature that everything seems to be part of one living organism."
(2) Mysticism is "the science or art of the spiritual life" [24]. It is a measure of one's willingness to be interested in things that cannot be explained by rationale and reason.

(3) Self-forgetfulness is what we experience in full play. Selfforgetfulness is also characterized by tendency to experience altered states of consciousness [5].

Those of us who are more self-forgetful have an easier time getting lost in the moment, being absorbed in art and music and sport, in achieving Csikszentmihalyi's flow state.

So, flow states are not just at the heart of much of human performance - but also a crucial component of our self transcendence.

\subsection{Role of Technology Support}

"What is a LIMITS-aligned computing system?" In the LIMITS community, we encourage authors to submit either a Hypothetical Systems paper or a Transitional Systems paper - and yet the very act of proposing one always makes me reflect on when the implication is not to design [1].

In support of this critical reflective discussion culture we have at LIMITS already, let's consider the stories we tell and reify through their work, because "Stories have power". In the words of Sasha Costanza-Chock [6], we get to explore what stories are told about design problems, solutions, contexts, and outcome. We also get to observe who gets to tell these stories, and add our own to it. We get to explore who participates, who benefits, and who is harmed by the systems we propose and consider developing.

As technology researchers we have a shared responsibility to look into the narratives promoted in the world in order to call attention to the way how technology developers influence and shape the world around them by the systems they put out. As designers, we have power, and with that power comes responsibility.

\subsection{Storytelling}

The "Power of storytelling" by Thomas Newman [21] is based on paediatrics and infant safety, but the insights hold as much for the stories we tell within the LIMITS research community:

(1) The brains of human beings seem built to process stories better than other forms of input.

(2) The storytellers themselves are important, as it enables a connection with the listener or reader beyond what would be possible if the story were recounted by a dispassionate observer.

The numbers of my research for this auto-ethnographic study would be meaningless if I presented them without a context and a story to be told. We learn more from stories than from numbers, and we can have meaningful conversations and deeper understanding based on the connection that gets established by a shared story.

\section{THE PURSUIT OF ESSENCE IN THREE ACTS}

\subsection{Autoethnographic approach: Daily journaling}

I have been journaling for the largest part of my life ever since I received a journal as a present for my 11th birthday. I write 15-30 minutes of reflective notes almost every day. They allow me to go deeper into internal processes and find my way through challenges 


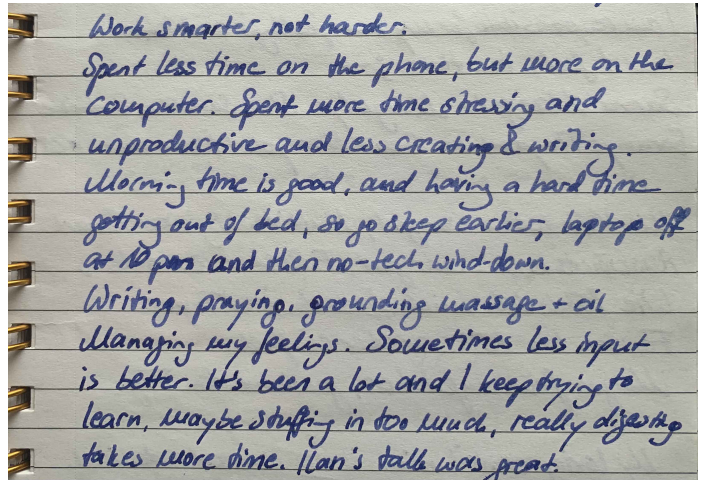

Figure 2: Entry from October 24th, 2020

that come up on a mental or emotional level. For the largest part, I am taking these notes manually, which has resulted in a significant stack of filled notebooks over the years. When I move countries, I reduce that amount as a process of letting go of the past, because I rarely look back beyond two years in these notes, and manual notes written in a linear fashion without additional markup are hard to search.

For the summary of internal processes in this paper, I reread the notes of the past year, deducted the overarching story-line related to the topic under investigation (as I wrote about many other things as well) and pulled out quotes to illustrate the points.

I explicitly acknowledge that I am in the privileged position of having a steady job that allows me a roof over my head and food on the table, so my reflections on expansion and oneness are informed by the experience of that privilege in my life, and yet I hope that the observations can be of interest to the community and beyond for a discussion on what is essential to us and how to navigate limits internally and externally.

\subsection{Alone Together: Lock-down?}

Alone together is a phrase that came to mind many times when connecting to others during the times of the pandemic. I am writing this as if it was over and we had moved on, while the truth is that the numbers are worse than ever before in the country I live in. Sweden took a controversial approach to dealing with this virus, attempting herd immunity, but a year into this, we are none with wiser and no-one knows whether we are more immune than anyone else. We are living day to day making the best of what we can do, reaching out to each other and supporting ourselves, loved ones, friends, colleagues and students in the best way we can. For the time that we do spend separate, we notice that the time we spend online and on devices has gone up.

I am fairly well self-regulated and have a lot of practice in going inward. At the beginning of the pandemic, there was a significant shift in my personal life that required a lot of digesting and being with myself. So I took the restricted circumstances as invitation to inquire deeply inward, hours in meditation, taking courses to grow further internally. From the first few months of being hosted at a wonderful friend's place due to the lock-downs ensuing while I was abroad, I managed to visit my parents for my youngest brother's

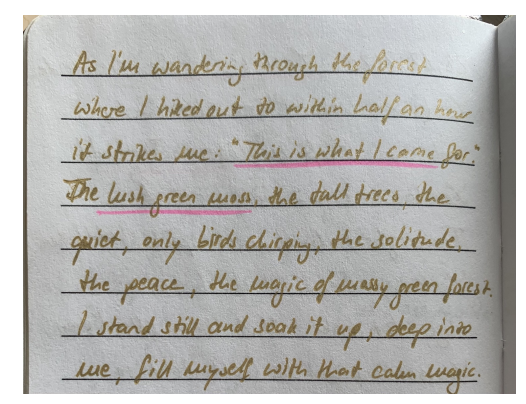

Figure 3: Entry from December 28th, 2020

wedding celebration, and finally faced returning to my empty apartment in a city I hadn't yet spent much time in.

I noticed several ways of how I was using technology differently now:

(1) I worked $100 \%$ on the computer, no printer at home, no faceto-face meetings, so everything I did was on a laptop, and that was straining.

(2) I used technology for entertainment way more via videos, books and podcasts because my favorite pastimes are based around engaging with people (acro yoga, rock climbing, dancing) and were not available.

(3) I learned online via courses and videos and podcasts until I coudn't take in more (desire for expansion).

(4) I was plugged in almost constantly as I used my long walks to talk on the phone to friends and family to offset the lack of direct interaction (desire for oneness).

At the beginning of the period of personal isolation in that apartment, I felt kind of in a hermitage and processing a lot of the things that had been going on in my life and trying to understand the new directions I was being asked to take. In the excerpt in Fig. 2, there are both tendencies, the reference to self-care via writing, praying, grounding massages, and managing my feelings, but also the reference to working too long hours, and much time stressing and trying to cram in too many (online) activities. After spending four months in isolation and online time continuously creeping up, I went offline and off technology for a full two weeks over Christmas and the New Year.

\subsection{Going Dark: Locked out?}

It was a period that is often referred to as a dark night of the soul, where we face our pains in order to let them pass through us. There was the part in me that wanted to be the light warrior and come out strong on the other end, and there was the part that just knew I had to surrender more deeply. In between all my practices of meditation, yoga asana, breathing, and reflecting and journaling, I knew there was a magic piece that was somehow missing.

So what happens when I lock myself out of all the connecting technology that helped overcome the separation felt during the locked down period of the year? All of a sudden, there is an experience of freedom. The freedom experienced when I set a boundary. It is so interesting how boundaries provide freedom - I see that in relationships, in raising children, and in work environments. The 
boundary is a contract that makes one feel connected, and it allows for seeking expansion in different ways and engages creativity.

I spent many hours per day in nature - pretty much all the time there was daylight, because in Sweden the days are short in December and January. I was hiking in the lush green forest, biking along the coast, watching the seagulls fly by and the clouds do their dance, and meditating an hour every morning and every evening. I had never in my life spent that much time alone or offline, and the combination of both together felt both intense and also sacred, because I didn't know whether life would ever offer that opportunity again. The excerpt in Fig. 3 reports on one of many beautiful moments in nature during that period, and even re-reading it months later has me recall that feeling.

This is another paragraph I wrote during that offline period, just after the New Year, on January 2nd:

"I am deeply inspired after a few months of an intense continuous dive into spiritual teachings and practices, of practicing loving kindness, of consoling myself when I was sad, of finding joy in little moments of preciousness in nature, in connection, in creation. This year has taught me many things, it has felt incredibly vulnerable and I am raw, and I will continue to peel back the layers instead of putting armour on. I won't shield myself - whatever comes my way I'll be here with open arms, ready to breathe deeply with it and learn and love."

It feels somewhat out of place in a research paper, yet as an auto-ethnographic element, it makes sense. It also explains why maybe there are not so many auto-ethnographic studies out there in my field - they require us to look deep and be vulnerable.

At the same time it is a take on life that I stand by, and that I aspire to continue practicing every day. Maybe it should be published, maybe I do want the world to know, maybe especially researchers and engineers that come across it find it useful to read and either feel seen themselves or get inspired to take a fresh look at their own perspective. I do not know. I am curious to explore it though.

\subsection{The Matrix: Locked in?}

After the offline period, I returned to work life and being back in touch online at a measured pace, and could watch that pace slowly creeping up over the next few weeks until it was almost back to pre-break pace. In the excerpt in Fig. 4, I describe how I catch myself over and over getting distracted by pop-ups and notifications and my dissatisfaction with them. I observed that not even switching off the notifications on the phone helped that much, because the mere appearance of the app icons would often tempt me into just 'looking for a moment what's up' and then ending up in a rabbit hole. That made me think of not only how self-discipline comes in, but also how these apps are designed to be attentive-hooking, addictive, and to an almost repulsed reaction to technology. That lead to pondering on reevaluating life plans and ways of living, see Fig. 5.

While I have been exceptionally fortunate in many regards in my situation (no one really close to me died in this pandemic and I still have my job) and am grateful for that, I do not want to pretend there wasn't a lot of strain that living alone in a pandemic in a

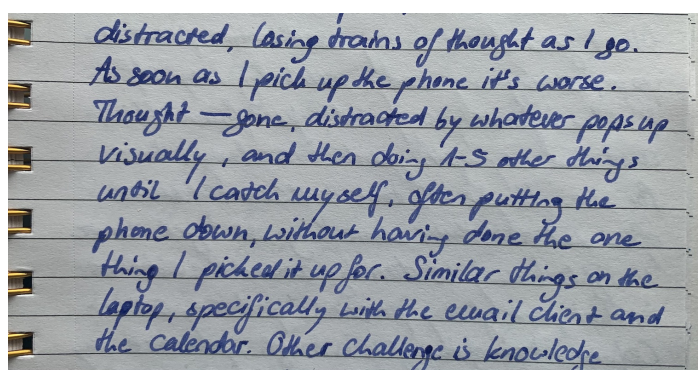

Figure 4: Entry from January 14th, 2021

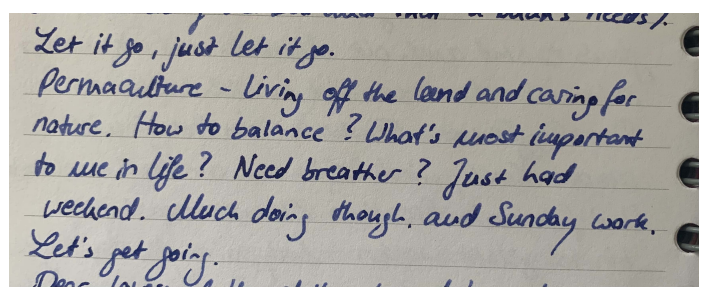

Figure 5: Entry from March 22nd, 2021

rather new city placed on me, and many people I have spoken to in the last year suffer from it. At the same time, moving everything online for work and socializing makes it very tempting to spend a large amount of time 'plugged in'. So much, that it does remind me of the 'Matrix' movie ${ }^{1}$.

Nevertheless, I find technology does hold valuable opportunities to support us in many tasks and pursuits, so let's look into a few I have found valuable over the past year to support me in the desires for oneness and expansion.

I used technology for flow and focus support, to pursue the essence of realizing expansion and oneness, in various reductionist approaches. I call them reductionistic, because my preference tends to be on technology support that is limited in its interactivity rather than encompassing. For example, I find immersive environments like virtual realities overwhelming, and I have never been a gamer. I prefer limited user interfaces. The ones discussed here are:

- Insight Timer, a guided meditation app ${ }^{2}$

- Clubhouse, an audio-only social network

- Muse, a neuro-feedback app

- the Breathing App, a breathing practice support

- ReMarkable, an e-ink tablet

- Podcasts, audio-only 'edutainment' (in my selection)

In Table 1, I list each of the apps individually, how its usage contributes to fulfilling the human desires for oneness and expansion, and how this is limited in the technological realization. In summary, the apps cover supporting all three major aspects of oneness (connection, intimacy, and support) as well as expansion (freedom, growth, and expression) - in a way perceived by the author, which may be different for other users. If I were to summarize the limitations in one, it would come back to the sense of being plugged into 'the Matrix'.

\footnotetext{
${ }^{1}$ https://www.imdb.com/title/tt0133093/

${ }^{2}$ https://insighttimer.com/blove
} 


\begin{tabular}{r|l|l|l}
\hline App & Oneness & Expansion & Limitation \\
\hline \hline Insight Timer & $\begin{array}{l}\text { Connection to self, support through } \\
\text { community }\end{array}$ & $\begin{array}{l}\text { Growth through self observation and } \\
\text { reflection }\end{array}$ & More 'screen time' \\
\hline Clubhouse & Intimate sharing in community & Learning, expression of views & $\begin{array}{l}\text { Addiction potential, follower culture } \\
\text { versus real expertise }\end{array}$ \\
\hline Breathing App & Intimate connection to mind and body & $\begin{array}{l}\text { Improving practice by neuro-feedback } \\
\text { rience of turning inward }\end{array}$ & $\begin{array}{l}\text { Additional hardware (headband) and } \\
\text { feeling of 'plugged in' }\end{array}$ \\
\hline ReMarkable & $\begin{array}{l}\text { Deep focus via reduced interaction } \\
\text { and no distraction }\end{array}$ & Expression of ideas and creativity & $\begin{array}{l}\text { Additional hardware, haptics different } \\
\text { from 'real' pen and paper, 'hidden' re- } \\
\text { sults as on computer }\end{array}$ \\
\hline \hline & $\begin{array}{l}\text { Connection to like-minded commu- } \\
\text { nity, coaching and support }\end{array}$ & $\begin{array}{l}\text { Growth through learning, freedome } \\
\text { through discovery }\end{array}$ & Consistent input requires sink-in time \\
& $\begin{array}{l}\text { pects of oneness: connection, inti- } \\
\text { macy, and support }\end{array}$ & $\begin{array}{l}\text { Touching upon the three major as- } \\
\text { pects of expansion: freedom, growth, } \\
\text { and expression }\end{array}$ & \\
\hline \hline
\end{tabular}

Table 1: Overview of Tools the Author Used for Oneness and Expansion Exploration and their Limitations

Consequently, there can be support by technology for "pursuing the essence", but it is highly dependent on individual usage and healthy boundaries. The observations are connected to related work and other research in the following section.

\section{DISCUSSION: THE RED PILL AND THE BLUE PILL}

\subsection{Insights from Related Work}

Desires and Technology Based on the 16 desires by Reiss [22], Cheikh-Ammar and Barki [2] created their Desirability framework for "Individual/Technology Fit", which denotes how well a technology product fits the individual user. It uses the desires to explain the non-rational perspective of post-adoption behavior beyond notions of task performance. Cheikh-Ammar and Barki are mostly interested in evaluating the continued use of technology with an improved measure, while the paper at hand discussed how well a number of examples is aligned with supporting the desires for oneness and expansion in the pursuit of the essence and flow, and where and how technology support contradicts that pursuit.

Boundaries in Technology As noted in the 'Going Dark" section, healthy boundaries offer freedom, which is also experienced by digital nomads - and I kind of turned into one in my home office. Cook [4] discovered that, in practice, digital nomadism is not always experienced as autonomous and free but is a way of living that requires high levels of discipline and self-discipline.

A first open question to live into is how to re-establish healthy boundaries in between work and private life such that we are connected when required and in recharge mode when available. Such boundaries also apply to community, service to others, volunteering, etc.

\subsection{Insights from Neuroscience and Flow on Technology}

David Eagleman says neuroplasticity should better be called livewiring because the term originally stemmed from plastic being molded into shape . but plastic then stays that way, while our brain does not [8]. Our brains constantly adapt and rewire themselves, according to what he calls the "Mr. Potato Head Theory" of neuroplasticity. It describes how a blind person can adapt their unused visual cortex to process taps from a cane, or boost their hearing. He also adds that we all do it, all the time, and it takes as little as an hour to do so, proven in a long line of clinical studies described in the book [8].

This, in Jamie Wheal words [25] "unlocks the secret of Clubhouse and its billion dollar valuation for something as low-tech as AM talk radio, and as intimate as our old campfire yarnings of our ancient past. In as little as an hour, our strained eyes, and over-filtered selves get to shut off the barrage of visual and digital stimuli and tune in to the Word-Sound-Power of other humans in real time."

A second question to live into is how to incorporate the curiosity of sensory deprivation such that we can perceive the benefits of our self-regulating brain, stimulating by limiting our sensory input of some sorts, to let it show its creative magic.

\subsection{Insights from Play}

As kids, we play with all of our being. We forget ourselves (see self-transcendence in Sec. 2.4). The 'Now' swallows us whole.

Andy Huberman, a neuro-science professor from Stanford, describes in his podcast ${ }^{3}$ that neuroplasticity is triggered by intense focus, but occurs during deep rest and sleep. The brain likes to release as much to default as possible and pass it off to reflexive behavior, but we have to pay attention to duration, path, and outcome. We have to be very careful about how much we make our dopamine reward dependent on external motivation instead of internal motivation. There is a need to balance between dopamine

\footnotetext{
${ }^{3}$ https://hubermanlab.libsyn.com/how-to-focus-to- change-your-brain-episode- 6
} 
(outward search and pursuit) and serotonin (inside fulfillment and safety feeling).

He explains it with kids at play: Dopamine is the will to live, for example look at kids playing, they experience it all the time full-on, and then need deep rest to reset. This is why playful learning is so effective. The dopamine gets increased when we have a big goal, an intention or 'why' being on pursuit - which is why it is easier to learn a language when you have a foreign partner - it motivates on a different reward level. Serotonin resets the dopamine level, so that we can increase that again and fully show up. Gratitude increases serotonin levels - that is why regular gratitude practice is so effective. Huberman concludes that learning how to control our autonomous nervous system better is going to be the next step step in human evolution [14].

The third open question to live into is how we can include more playfulness in our daily lives.

\section{CONCLUSION: THE REMAINING ESSENCE}

Essentialism, the disciplined pursuit of less [20], means we always get to look at our current metaphorical plate, and as soon as there's too much on it (note: for many of us, that is a way too familiar state), let's lean back and question it.

\subsection{Living into the Questions}

What remains? Every time we get knocked out in life, whether due to illness or a death of a loved one, all of a sudden we learn that we can drop a lot of things when needed. It is suddenly possible to cancel meetings and unwanted obligations, to say no to things, to take care of ourselves, to ask for help, and to eventually reevaluate where we want to take our life next. Can we allow ourselves to take that step before things fall apart? Can we love ourselves enough to reevaluate what oneness and expansion mean to us personally and how we want to live into them?

Bringing it back into the ecological context of limits, in the words of Kimmerer [17, p. 31]: "How, in our modern world, can we find our way to understand the earth as a gift again, to make our relations with the world sacred again? I know we cannot all become huntersgatherers - the living world could not bear our weight - but even in a market economy, can we behave " as if" the living world were a gift?"

\subsection{The Hypothetical System}

We promised we would point out resulting questions and wonder how to live into them via a proposed hypothetical system. Resulting questions are:

(1) How to re-establish healthy boundaries in between work and private life such that we are connected when required and in recharge mode when available.

(2) How to incorporate the curiosity of sensory deprivation such that we can perceive the benefits of our selfregulating brain, stimulating by limiting our sensory input of some sorts, to let it show its creative magic.

(3) How we can include more playfulness in our daily lives, such that we experience the full being in the moment and can learn like kids, and then sleep knocked out for a full night.
Does it even need a technology support for that? Is it a little reminder system for when to unplug? Is it a magical unplug button that disconnects out automatically and throws us back into the Deep Now in unexpected ways? We could almost imagine a random generator that prescribes some white space to help us recharge. How would that work in contrast to us self-regulating our recharge time in an epoch when mental health is facing serious challenges? If we are not that good at taking recharge time ourselves, would a prescription help? Or would we press 'snooze' like we do on other reminders?

Looking back at my reflective process and re-reading this paper again after a period of reviewing for preparing the final version, I am convinced that it is about the limits and boundaries that we wish to set for ourselves in a responsible way of self-care and self-love. So I don't want to even propose a hypothetical system other than ways that limit our use of technology to an extent that still benefits us as individuals and collective. Currently, both individuals and collective in my personal sphere of experience tend to be plugged in too much, and therefore I will continue to set boundaries for myself in technology usage, while still applying it to connect with others, to carry out research, and to share experiences.

\subsection{Take Away}

While my personal conclusion led me to using technology less and setting boundaries, maybe there are others in the research community that find new ways for how some of the questions raised in this paper can be addressed by designing a system that would help others live into them.

Either way, I wish to invite you to surrender into oneness as well as into expansion, in a playful way allowing for flow. Oneness and expansion collide in the most beautiful way, and they support us in going beyond our anxiety and mental health crisis, and in remembering our inherent bliss.

\section{ACKNOWLEDGEMENT}

My big thanks to Lisa Nathan and Alan Borning for very thoughtful feedback and suggestions on how to improve an earlier version of this paper. I am grateful for the LIMITS research community, where open and constructive reviews have brought the community closer together and provide a strong foundation for fruitful discussions at the workshops and in between.

\section{REFERENCES}

[1] Eric PS Baumer and M Six Silberman. 2011. When the implication is not to design (technology). In Proceedings of the SIGCHI Conference on Human Factors in Computing Systems. 2271-2274.

[2] Mustapha Cheikh-Ammar and Henri Barki. 2013. When technology meets human desires. (2013)

[3] C Robert Cloninger, Dragan M Svrakic, and Thomas R Przybeck. 1993. A psychobiological model of temperament and character. Archives of general psychiatry 50, 12 (1993), 975-990.

[4] Dave Cook. 2020. The freedom trap: digital nomads and the use of disciplining practices to manage work/leisure boundaries. Information Technology \& Tourism (2020), 1-36.

[5] Rui Miguel Costa, José Pestana, and David Costa. 2018. Self-Transcendence, sexual desire, and sexual frequency. Journal of sex \& marital therapy 44, 1 (2018), $56-60$.

[6] Sasha Costanza-Chock. 2020. Design justice: Community-led practices to build the worlds we need. The MIT Press.

[7] Mihaly Csikszentmihalyi. 2013. Flow: The psychology of happiness. Random House. 
[8] David Eagleman. 2020. Livewired: The inside story of the ever-changing brain Canongate Books.

[9] Viktor E Frankl. 1966. Self-transcendence as a human phenomenon. fournal of Humanistic Psychology 6, 2 (1966), 97-106.

[10] Danilo Garcia, Nigel Lester, Kevin M Cloninger, and C Robert Cloninger. 2017 The temperament and character inventory (TCI). Encyclopedia of personality and individual differences. Cham: Springer (2017), 1-3.

[11] Albert Garcia-Romeu. 2010. Self-transcendence as a measurable transpersonal construct. Fournal of Transpersonal Psychology 42, 1 (2010), 26

[12] Jasper Thomas Garrett and Michael Tlanusta Garrett. 1996. Medicine of the Cherokee: The way of right relationship. Simon and Schuster.

[13] Jason Hickel. 2020. Less is more: How degrowth will save the world. Random House.

[14] Andrew Huberman. 2021. Huberman Lab. https://hubermanlab.libsyn.com.

[15] Jon Kabat-Zinn. 2012. Mindfulness for beginners: Reclaiming the present moment-and your life. Sounds True.

[16] Giorgos Kallis. 2019. Limits: Why Malthus was wrong and why environmentalists should care. Stanford University Press.
[17] Robin Wall Kimmerer. 2013. Braiding sweetgrass: Indigenous wisdom, scientific knowledge and the teachings of plants. Milkweed Editions.

[18] Steven Kotler. 2021. The Art of Impossible. Harper Wave.

[19] Abraham Harold Maslow. 1971. The farther reaches of human nature. Vol. 19711. Viking Press New York.

[20] Greg McKeown. 2020. Essentialism: The disciplined pursuit of less. Currency.

[21] Thomas B Newman. 2003. The power of stories over statistics. Bmj 327, 7429 (2003), 1424-1427.

[22] Steven Reiss. 2004. Multifaceted nature of intrinsic motivation: The theory of 16 basic desires. Review of general psychology 8, 3 (2004), 179-193.

[23] Johan Rockström, Will Steffen, Kevin Noone, Åsa Persson, F Stuart Chapin III, Eric Lambin, Timothy M Lenton, Marten Scheffer, Carl Folke, Hans Joachim Schellnhuber, et al. 2009. Planetary boundaries: exploring the safe operating space for humanity. Ecology and society 14, 2 (2009).

[24] Evelyn Underhill. 1930. Mysticism. Methuen.

[25] Jamie Wheal. 2021. Newsletter. https://www.homegrownhumans.us.

[26] Ashley V Whillans and Elizabeth W Dunn. 2019. Valuing time over money is associated with greater social connection. Journal of Social and Personal Relationships 36, 8 (2019), 2549-2565. 